\title{
Correlation of return to work with patient satisfaction after surgery for lumbar spondylolisthesis: an analysis of the Quality Outcomes Database
}

\author{
Anthony M. DiGiorgio, DO, MHA,,2 Praveen V. Mummaneni, MD, ${ }^{1}$ Paul Park, MD, ${ }^{3}$ \\ Andrew K. Chan, MD, ${ }^{1}$ Erica F. Bisson, MD, MPH, ${ }^{4}$ Mohamad Bydon, MD, ${ }^{5}$ Kevin T. Foley, MD, ${ }^{6}$ \\ Steven D. Glassman, MD, ${ }^{7}$ Christopher I. Shaffrey, MD, ${ }^{8}$ Eric A. Potts, MD, ${ }^{9}$ Mark E. Shaffrey, MD, ${ }^{10}$ \\ Domagoj Coric, MD, ${ }^{11}$ John J. Knightly, MD, ${ }^{12}$ Michael Y. Wang, MD, ${ }^{13}$ Kai-Ming Fu, MD, PhD, ${ }^{14}$ \\ Anthony L. Asher, MD, ${ }^{11}$ Michael S. Virk, MD, PhD, ${ }^{14}$ Panagiotis Kerezoudis, MD, MS, ${ }^{5}$ \\ Mohammed Ali Alvi, MBBS, ${ }^{5}$ Jian Guan, MD, ${ }^{15}$ Regis W. Haid Jr., MD, ${ }^{16}$ and \\ Jonathan R. Slotkin, MD ${ }^{17}$ \\ 1Department of Neurological Surgery, University of California, San Francisco, California; ${ }^{2 B}$ rain and Spinal Injury Center, \\ Zuckerberg San Francisco General Hospital, San Francisco, California; ${ }^{3}$ Department of Neurologic Surgery, University of \\ Michigan, Ann Arbor, Michigan; ${ }^{4}$ Department of Neurological Surgery, University of Utah, Salt Lake City, Utah; ${ }^{5}$ Department \\ of Neurologic Surgery, Mayo Clinic, Rochester, Minnesota; ${ }^{6}$ Department of Neurosurgery, University of Tennessee, Memphis, \\ Tennessee; 7 Norton Leatherman Spine Center, Louisville, Kentucky; ${ }^{8}$ Departments of Neurological Surgery and Orthopedic \\ Surgery, Duke University, Durham, North Carolina; ${ }^{\circ}$ Department of Neurological Surgery, Goodman Campbell Brain and Spine, \\ Indianapolis, Indiana; ${ }^{10}$ Department of Neurological Surgery, University of Virginia Health System, Charlottesville, Virginia; \\ ${ }^{11}$ Neuroscience Institute, Carolina Neurosurgery and Spine Associates, Carolinas HealthCare System, Charlotte, North Carolina; \\ ${ }^{12}$ Atlantic Neurosurgical Specialists, Morristown, New Jersey; ${ }^{13}$ Department of Neurological Surgery, University of Miami, Florida; \\ ${ }^{14}$ Department of Neurological Surgery, Weill Cornell Medical Center, New York, New York; ${ }^{15}$ Pacific Neurosciences Center, \\ Torrance, California; ${ }^{16}$ Atlanta Brain and Spine Care, Atlanta, Georgia; and ${ }^{17}$ Geisinger Health, Danville, Pennsylvania
}

OBJECTIVE Return to work (RTW) and satisfaction are important outcome measures after surgery for degenerative spine disease. The authors queried the prospective Quality Outcomes Database (QOD) to determine if RTW correlated with patient satisfaction.

METHODS The QOD was queried for patients undergoing surgery for degenerative lumbar spondylolisthesis. The primary outcome of interest was correlation between RTW and patient satisfaction, as measured by the North American Spine Society patient satisfaction index (NASS). Secondarily, data on satisfied patients were analyzed to see what patient factors correlated with RTW.

RESULTS Of 608 total patients in the QOD spondylolisthesis data set, there were 292 patients for whom data were available on both satisfaction and RTW status. Of these, 249 (85.3\%) were satisfied with surgery (NASS score 1-2), and 224 (76.7\%) did RTW after surgery. Of the 68 patients who did not RTW after surgery, 49 (72.1\%) were still satisfied with surgery. Of the 224 patients who did RTW, 24 (10.7\%) were unsatisfied with surgery (NASS score 3-4). There were significantly more people who had an NASS score of 1 in the RTW group than in the non-RTW group $(71.4 \%$ vs $42.6 \%$, p < 0.05). Failure to RTW was associated with lower level of education, worse baseline back pain (measured with a numeric rating scale), and worse baseline disability (measured with the Oswestry Disability Index [ODI]).

CONCLUSIONS There are a substantial number of patients who are satisfied with surgery even though they did not RTW. Patients who were satisfied with surgery and did not RTW typically had worse preoperative back pain and ODI and typically did not have a college education. While RTW remains an important measure after surgery, physicians should be mindful that patients who do not RTW may still be satisfied with their outcome.

https://thejns.org/doi/abs/10.3171/2020.2.FOCUS191022

KEYWORDS lumbar spondylolisthesis; patient satisfaction; return to work; spine surgery; Quality Outcomes Database

ABBREVIATIONS MCID = minimal clinically important difference; NASS = North American Spine Society patient satisfaction index; NRS = numeric rating scale; NRS-BP = NRS for back pain; NRS-LP = NRS for leg pain; ODI = Oswestry Disability Index; PRO = patient-reported outcome; $Q O D=$ Quality Outcomes Database; RTW = return to work.

SUBMITTED December 31, 2019. ACCEPTED February 7, 2020.

INCLUDE WHEN CITING DOI: 10.3171/2020.2.FOCUS191022. 
$\mathrm{T}$ HERE are many measures of success after spine surgery. Some, such as patient satisfaction, are highly subjective, while others, like return to work (RTW), are objective. Having a satisfied patient population and a high rate of RTW are important goals after spine surgery. However, few studies have examined how these two outcomes are related.

RTW after surgery benefits patients, payors, employers, and society. Patients who RTW have improved mental well-being and continued income. ${ }^{11,15}$ Payors, employers, and society benefit from less disability and higher participation in the workforce. ${ }^{10}$ The goals of lumbar spine surgery should, whenever possible, include having patients RTW postoperatively. Indeed, many studies have investigated factors that either improve or worsen RTW rates after spine surgery. $8,13,14,16,20,28$

However, while RTW benefits patients, employers, payors, and society, subjective patient satisfaction is an important outcome as well. In lumbar spine surgery, patient satisfaction is often measured by the North American Spine Society patient satisfaction index (NASS) score, as follows: 1 , surgery met my expectations; 2 , I did not improve as much as I had hoped but I would undergo the same operation for the same results; 3 , surgery helped but I would not undergo the same operation for the same results; and 4, I am the same or worse than before surgery. This scoring system, developed by Daltroy et al. in 1996, has shown solid reliability and validity across multiple languages. ${ }^{7,1921}$ Like RTW, other factors that contribute to patient satisfaction after spine surgery have been examined in many studies. ${ }^{4-6,18}$

In total, $49 \%$ of Americans have health insurance through their employer, eclipsing the $34 \%$ insured by Medicare and Medicaid combined. ${ }^{12}$ Employers strive to have a healthy, engaged workforce. Some employers like Walmart, Lowes, McKesson, and others even direct their employees to designated centers of excellence for spine and other surgeries. These centers often use registries to track metrics for certain procedures and show acceptable outcomes. ${ }^{22,23,27}$ Both RTW and patient satisfaction are metrics which are important to public and private payors and are also easy for patients to understand.

The Quality Outcomes Database (QOD) is one registry that prospectively tracks both RTW and satisfaction after a variety of neurosurgical procedures. The data collected for spine surgery have proven useful in modeling which patients are likely to $\mathrm{RTW}^{2}$ and which are most likely to be satisfied after surgery for lumbar degenerative disease. ${ }^{6,18}$ No QOD studies have yet examined how satisfaction relates to RTW, and if these two outcomes are correlated. Understanding how these two outcomes correlate may prove useful to payors, employers, and patients in evaluating the utility of lumbar spine surgery. In this study we queried the QOD to determine if RTW and satisfaction are correlated and how they both relate to another validated outcome metric, the Oswestry Disability Index (ODI). Additionally, this study examined the time course of these two variables to see if patients become more satisfied as they returned to work or vice versa.

\section{Methods}

The QOD is a prospective longitudinal registry that tracks clinical data and outcomes from several neurosurgical procedures, including surgery for lumbar spondylolisthesis. Twelve of the highest-enrolling sites participate in a project specifically examining this pathology. This focus on lumbar spondylolisthesis allows the registry to track practice patterns and results of high-volume neurosurgical and orthopedic practices. The outcomes are collected directly from patients through surgeons' offices, typically via a study coordinator. The 12 sites participating in the lumbar spondylolisthesis project have enacted vigorous auditing methods to ensure data accuracy, including evaluation of preoperative lumbar radiographs to confirm the diagnosis of spondylolisthesis. ${ }^{3-6,17,18}$ We chose to analyze the lumbar spondylolisthesis data set for our study. Inclusion criteria for the study have been published previously ${ }^{4}$ and included patients who underwent single-segment surgery (i.e., a single disc level) for Meyerding grade 1 degenerative lumbar spondylolisthesis between July 2014 and June 2016.

Variables for which data are collected in the QOD include demographics (age and sex), BMI, ethnicity, insurance, educational level, preoperative employment, comorbidities, American Society of Anesthesiologists (ASA) classification grade, clinical symptoms, surgical variables (approach, technique, blood loss, operative time, length of hospitalization), and patient-reported outcomes (PROs). The PROs that are collected include the ODI, EQ-5D, numeric rating scale for back pain (NRS-BP) and leg pain (NRS-LP), and NASS scores. PROs are collected at baseline and postoperatively at 3,6,12, and 24 months.

For the purposes of our study, NASS scores of 1-2 were categorized as "satisfied" and scores of 3-4 as "unsatisfied." This binary categorization allowed us to distinguish patients who may be willing to undergo surgery again (NASS scores 1 and 2) versus those not willing to undergo surgery again (NASS scores 3 and 4). Although PROs are collected at multiple time points postoperatively, not all of these data are available for every patient; the latest available PROs, including NASS score for a given patient, were utilized for data analysis. Patients were considered to be in the RTW group for RTW at any time during their available follow-up period.

Univariate analysis of the satisfied patients was performed by comparing those who did RTW to those who did not RTW at any time during follow-up across the following variables: age, sex, smoking status, BMI, presence of comorbidities (diabetes, coronary artery disease, depression, osteoporosis), educational level, and baseline PROs (NRS-BP, NRS-LP, ODI, and EQ-5D scores).

ODI is a well-established measure for lumbar spine pathology and has an established minimal clinically important difference (MCID). ${ }^{3,9}$ Binomial logistic regression analysis was used to determine if satisfaction and RTW correlated with whether or not a patient met the ODI MCID. We chose 14.3 as the MCID for ODI given previously published work from QOD investigators. ${ }^{3}$ We chose to examine how RTW and satisfaction evolved over time and if these findings correlated with meeting the ODI MCID. 
TABLE 1. NASS scores and RTW status

\begin{tabular}{ccc}
\hline NASS Score & Did Not RTW $(n=68)$ & Did RTW $(n=224)$ \\
\hline 1 & $29(42.6 \%)$ & $160(71.4 \%)$ \\
\hline 2 & $20(29.4 \%)$ & $40(17.9 \%)$ \\
\hline 3 & $7(10.3 \%)$ & $11(4.9 \%)$ \\
\hline 4 & $12(17.6 \%)$ & $13(5.8 \%)$ \\
\hline
\end{tabular}

Values are presented as number of patients (\%).

\section{Results}

Of 608 total patients in the QOD spondylolisthesis data set, there were 292 patients for whom both satisfaction and RTW status data were available. Of these patients, 249 $(85.3 \%)$ were satisfied with surgery at the latest available follow-up (NASS score 1-2), and 224 (76.7\%) did RTW after surgery. Of the 68 patients who did not RTW after surgery, 49 (72.1\%) were still satisfied with surgery. Of the 224 patients who did RTW, $24(10.7 \%)$ were unsatisfied with surgery (NASS score 3-4). The differences in patient satisfaction between those who did and those who did not RTW was not statistically significant $(\mathrm{p}>0.05)$. When looking at individual NASS scores (Table 1), there was a significantly higher percentage of patients who had an NASS score of 1 in the RTW group than in the non-RTW group $(71.4 \%$ vs $42.6 \%, \mathrm{p}<0.05)$.

On univariate analysis of the satisfied patients (Table 2), failure to RTW was associated with lower level of education, worse baseline back pain (NRS-BP scores $7.68 \pm$ 2.31 vs $6.49 \pm 2.80, p=0.012$ ), and worse baseline disability (ODI scores $51.40 \pm 18.73$ vs $43.39 \pm 15.21, \mathrm{p}=0.002$ ).

We examined the time course of patients who had shown early RTW and satisfaction (at 3 months postoperatively). Our data showed that of the patients who did RTW at the 3-month mark, their satisfaction levels did not change much over the remaining follow-up visits (93.2\% were satisfied with surgery at 3 months, $89.7 \%$ at 12 months, and $91.3 \%$ were satisfied at 24 months). The patients who did not RTW by 3 months also showed consistent rates of satisfaction, with little change over the 24-month follow-up period. Of the patients who were satisfied with surgery at 3 months, $66.7 \%$ had returned to work by 3 months, $86.6 \%$ by 12 months, and $92.1 \%$ by 24 months. Unsatisfied patients also increased their RTW rates over time, but their rates never caught up to those of the satisfied patients (Fig. 1).

In binomial regression analysis comparing the ODI MCID to RTW and satisfaction (Table 3), meeting the ODI MCID at 3 months postoperatively correlated with patient satisfaction $(\beta=2.21, \mathrm{p}<0.001)$ but not with RTW $(\beta=0.45, p=0.117)$. At both 12 and 24 months, the ODI MCID correlated with both satisfaction (12 months: $\beta=$ $1.89, \mathrm{p}=0.001 ; 24$ months: $\beta=2.22, \mathrm{p}=0.003)$ and RTW (12 months: $\beta=1.26, p=0.008 ; 24$ months: $\beta=1.83, p=$ 0.019).

\section{Discussion}

A patient's likelihood of returning to work after surgery for lumbar spondylolisthesis is important to patients,
TABLE 2. Univariate analysis of the satisfied patients who did and those who did not RTW

\begin{tabular}{|c|c|c|c|}
\hline Variable & $\begin{array}{l}\text { Did Not RTW } \\
\quad(n=49)\end{array}$ & $\begin{array}{l}\text { Did RTW } \\
(n=200)\end{array}$ & $\begin{array}{c}\mathrm{p} \\
\text { Value }\end{array}$ \\
\hline Age in yrs & $57.84 \pm 13.07$ & $58.30 \pm 10.20$ & $0.744^{*}$ \\
\hline Female & $32(65.3 \%)$ & $102(51.0 \%)$ & $0.080 \dagger$ \\
\hline Dominant symptom & & & $0.392 \ddagger$ \\
\hline Back & $20(40.8 \%)$ & $85(42.5 \%)$ & \\
\hline Leg & $7(14.3 \%)$ & $43(21.5 \%)$ & \\
\hline Equal & $22(44.9 \%)$ & $72(36.0 \%)$ & \\
\hline Smoking & $9(18.4 \%)$ & $18(9.0 \%)$ & $0.136 \ddagger$ \\
\hline BMI, $\mathrm{kg} / \mathrm{m}^{2}$ & $31.63 \pm 7.52$ & $30.00 \pm 6.28$ & $0.167^{*}$ \\
\hline Diabetes & $5(10.2 \%)$ & $27(13.5 \%)$ & $0.640 \dagger$ \\
\hline Coronary artery disease & $7(14.3 \%)$ & $15(7.5 \%)$ & $0.159 \dagger$ \\
\hline Anxiety & $13(26.5 \%)$ & $31(15.5 \%)$ & $0.093 \dagger$ \\
\hline Depression & $12(24.5 \%)$ & $30(15.0 \%)$ & $0.135 \dagger$ \\
\hline Osteoporosis & $2(4.1 \%)$ & $10(5.0 \%)$ & $1.00 \dagger$ \\
\hline Education & & & $0.007 \ddagger$ \\
\hline$<\mathrm{HS}$ & $4(8.2 \%)$ & $2(1.0 \%)$ & $\S$ \\
\hline HS or GED & $21(42.9 \%)$ & $65(32.7 \%)$ & \\
\hline 2 yrs college & $11(22.4 \%)$ & $33(16.6 \%)$ & \\
\hline 4 yrs college & $9(18.4 \%)$ & $50(25.2 \%)$ & \\
\hline Postcollege & $4(8.2 \%)$ & $48(24.1 \%)$ & $\S$ \\
\hline NRS-BP baseline & $7.69 \pm 2.28$ & $6.58 \pm 2.85$ & $0.008^{*}$ \\
\hline NRS-LP baseline & $6.55 \pm 2.92$ & $6.48 \pm 2.86$ & $0.877^{*}$ \\
\hline ODI baseline & $51.23 \pm 18.62$ & $43.67 \pm 15.31$ & $0.003^{*}$ \\
\hline EQ-5D baseline & $0.526 \pm 0.233$ & $0.578 \pm 0.198$ & $0.120 *$ \\
\hline
\end{tabular}

GED = General Educational Development; $\mathrm{HS}$ = high school.

Values are presented as number of patients (\%) or mean \pm SD unless otherwise indicated. Boldface type indicates statistical significance.

${ }^{*}$ Student t-test.

$\dagger$ Fisher exact test.

$\ddagger$ Chi-square test.

$\S$ Subgroup differences $p<0.05$ by Bonferroni method.

payors, employers, and society. However, patient satisfaction is vital and should also be emphasized. Our data show there is a significant subset of patients who fail to RTW after surgery yet are still satisfied with their outcomes.

There is precedent for grouping NASS satisfaction index scores of 1-2 together into a "satisfied" group ${ }^{18}$ (i.e., the patients who would undergo surgery again), but we realize this may be controversial. When breaking it down by individual score, we did find that the RTW group did have a significantly higher percentage of patients with an NASS score of 1 . This finding suggests that the most satisfied individuals were also the patients who did RTW.

Other authors have examined RTW and satisfaction after lumbar fusion. Liow et al. also found similar rates of satisfaction in patients regardless of RTW status. ${ }^{14}$ This underscores our finding that patients who fail to RTW may still be satisfied with surgery. Other studies based on data from the QOD have found predictors for a low RTW rate (including high ODI and NRS-BP scores at baseline along with jobs that involve manual labor) ${ }^{2}$ and high sat- 


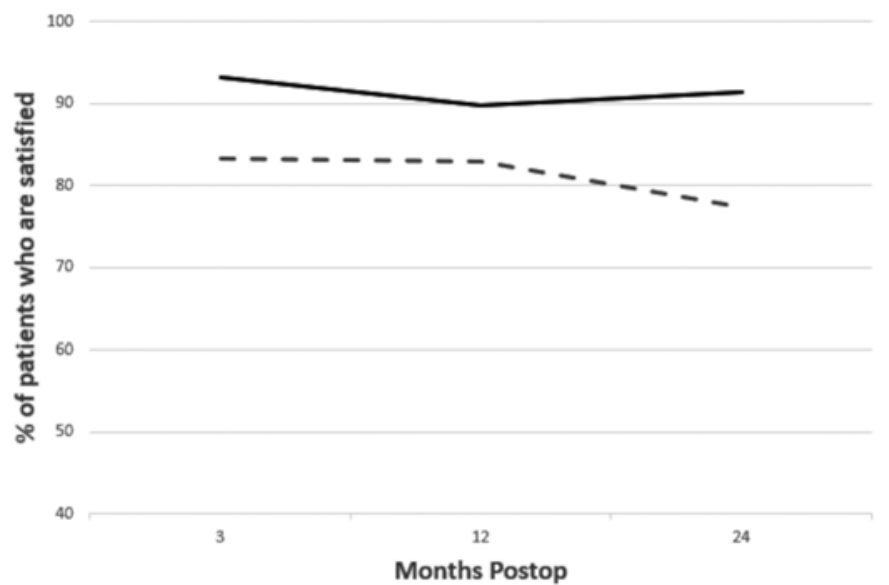

- - Non-RTW patients at 3 months _ RTW patients at 3 months

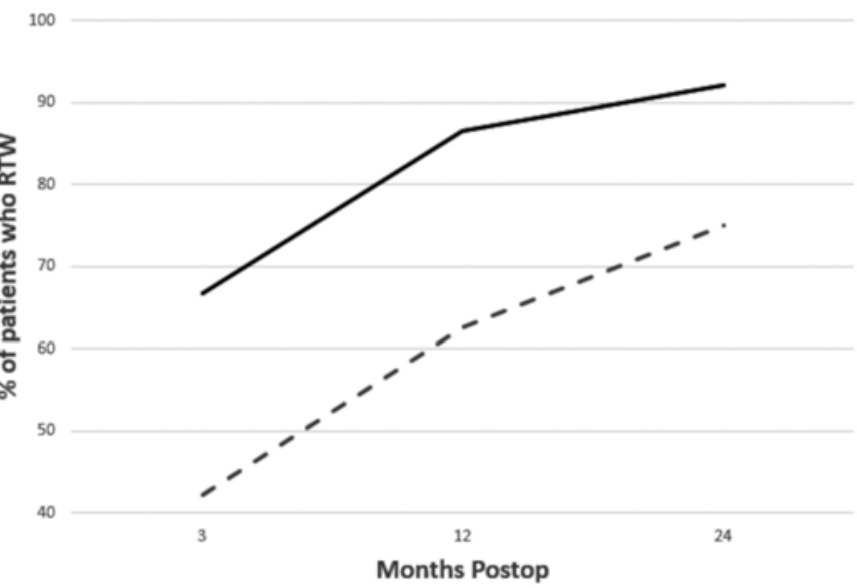

- - Unsatisfied Patients at 3 months _- Satisfied Patients at 3 months

FIG. 1. Left: Graph tracking the satisfaction level of the cohort of patients who did and those who did not RTW by 3 months postoperatively. Right: Graph tracking the RTW rate of the patients who were and those who were not satisfied with surgery at 3 months postoperatively.

isfaction rate (including predominant leg pain symptoms, being employed preoperatively, and being female). ${ }^{6}, 18$

Many studies have examined factors affecting RTW after spine surgery. Zakaria et al. showed that a positive preoperative screening for depression predicted the inability of patients to RTW and low satisfaction after lumbar fusion. ${ }^{28}$ Other authors have found similar findings. ${ }^{20}$ Further studies have found lower RTW rates for older patients, ${ }^{26}$ patients with workers' compensation who have legal representation, ${ }^{1}$ and patients who had a physically demanding job. ${ }^{13,24}$ Similar patterns have been found in patients who underwent cervical spine surgery. ${ }^{8}$ Unfortunately, the physical demands of the patients' jobs are not part of the QOD data set, so we are unable to tell if the satisfied patients who failed to RTW had manual labor jobs or not.

We examined satisfied patients who did not RTW after surgery. These patients tended to have lower educational levels and worse preoperative back pain (by NRS-BP) and disability (by ODI). But a significant subset of patients who did not RTW were still satisfied with their surgical outcome. While physicians should strive to help patients RTW after surgery, we should bear in mind that patient satisfaction also remains important.

By examining the change in RTW and satisfaction throughout the 24-month follow-up, we found that our data show that satisfaction usually precedes RTW. Of the

TABLE 3. Binomial regression model showing correlation of the ODI MCID with both patient satisfaction and RTW status at 3,12, and 24 months

\begin{tabular}{ccrcc}
\hline Time Point (mos) & Satisfaction $\beta$ & $p$ Value & RTW $\beta$ & $p$ Value \\
\hline 3 & 2.21 & $<0.001$ & 0.45 & 0.117 \\
\hline 12 & 1.89 & 0.001 & 1.26 & 0.008 \\
\hline 24 & 2.22 & 0.003 & 1.83 & 0.019 \\
\hline
\end{tabular}

satisfied patients, only $66.7 \%$ did RTW by 3 months. However, this cohort of patients showed an increasing RTW rate over time. A satisfied patient who did not RTW by 3 months had a $>90 \%$ chance of RTW by 24 months. Conversely, both the RTW and non-RTW cohorts at 3 months showed little change in their satisfaction rates over time (Fig. 1).

Our binomial regression model reinforced these findings. At 3 months postoperatively, meeting the ODI MCID correlated with patient satisfaction but not with RTW status. However, at 12 and 24 months postoperatively, meeting the ODI MCID correlated with both RTW and satisfaction. Thus, patients who had a significant reduction in their disability, as measured by ODI, were satisfied with their outcome at 3 months, even if they did not yet RTW. By 12 months postoperatively, patients who had a significant reduction in disability were satisfied with outcomes and did RTW. Tanenbaum has described this notion, discussing the merits of focusing on "proximate outcome measures" versus later ones. ${ }^{25}$ For payors to appreciate the value of lumbar surgery for spondylolisthesis, our data show that patients must be evaluated for at least 12 months postoperatively before RTW correlates with meeting the ODI MCID and patient satisfaction.

\section{Study Limitations}

Our study has some limitations. It is a retrospective review of a prospectively maintained registry. Most notably, of the 608 patients included in the original data set, we only had both RTW status and satisfaction scores on 292 patients. This is largely because not all of the patients were working preoperatively; 197 patients were categorized as "unemployed," and 28 were "employed but not working" according to the preoperative questions in the registry. The registry still had RTW status on 71 of these 225 patients. These patients were included in the study if they also had satisfaction scores. RTW status was either recorded as "not applicable" or left blank on 316 patients. 
These patients were excluded from our analysis, and this exclusion could represent a selection bias. The importance of this selection bias should not be understated, as the excluded patients (those not working prior to surgery) likely had the most severe disease.

Other variables that could affect outcomes were not available in the QOD. Notably, we did not have information on the patients' type of occupation. Jobs that require heavy manual labor have been shown to have different RTW rates than those without manual labor. We also did not have information on patients' socioeconomic status, another predictor of outcome. Additionally, the mean age for patients in the spondylolisthesis data set is 62 years, much older than the general working population. While there was no difference in age between the satisfied RTW and non-RTW patient populations, the advanced age of the patients in this study may represent an additional selection bias.

More research into patient satisfaction and RTW is needed. The factors influencing a patient's RTW after surgery are complex and further studies would benefit from detailed interviews. That type of qualitative data is beyond the scope of a registry-based study such as this one.

\section{Conclusions}

There are a substantial number of patients who are satisfied with lumbar spine surgery for spondylolisthesis although they did not RTW after surgery. Patients who were satisfied with surgery and did not RTW typically had worse preoperative back pain and ODI scores, with lower educational levels. Patient satisfaction correlates with meeting the ODI MCID earlier in the postoperative course. Both satisfaction and RTW correlate with meeting the ODI MCID by 12 months postoperatively. While RTW remains an important measure after surgery, physicians, employers, and payors should be mindful that patients who do not RTW may still be satisfied with their outcome.

\section{References}

1. Anderson JT, Haas AR, Percy R, Woods ST, Ahn UM, Ahn $\mathrm{NU}$ : Workers' compensation, return to work, and lumbar fusion for spondylolisthesis. Orthopedics 39:e1-e8, 2016

2. Asher AL, Devin CJ, Archer KR, Chotai S, Parker SL, Bydon M, et al: An analysis from the Quality Outcomes Database, Part 2. Predictive model for return to work after elective surgery for lumbar degenerative disease. J Neurosurg Spine 27:370-381, 2017

3. Asher AL, Kerezoudis P, Mummaneni PV, Bisson EF, Glassman SD, Foley KT, et al: Defining the minimum clinically important difference for grade I degenerative lumbar spondylolisthesis: insights from the Quality Outcomes Database. Neurosurg Focus 44(1):E2, 2018

4. Chan AK, Bisson EF, Bydon M, Glassman SD, Foley KT, Potts EA, et al: Laminectomy alone versus fusion for grade 1 lumbar spondylolisthesis in 426 patients from the prospective Quality Outcomes Database. J Neurosurg Spine 30:234241, 2018

5. Chan AK, Bisson EF, Bydon M, Glassman SD, Foley KT, Potts EA, et al: Obese patients benefit, but do not fare as well as nonobese patients, following lumbar spondylolisthesis surgery: an analysis of the Quality Outcomes Database. Neurosurgery 86:80-87, 2020
6. Chan AK, Bisson EF, Bydon M, Glassman SD, Foley KT, Potts EA, et al: Women fare best following surgery for degenerative lumbar spondylolisthesis: a comparison of the most and least satisfied patients utilizing data from the Quality Outcomes Database. Neurosurg Focus 44(1):E3, 2018

7. Daltroy LH, Cats-Baril WL, Katz JN, Fossel AH, Liang MH: The North American Spine Society lumbar spine outcome assessment instrument: reliability and validity tests. Spine (Phila Pa 1976) 21:741-749, 1996

8. Devin CJ, Bydon M, Alvi MA, Kerezoudis P, Khan I, Sivaganesan A, et al: A predictive model and nomogram for predicting return to work at 3 months after cervical spine surgery: an analysis from the Quality Outcomes Database. Neurosurg Focus 45(5):E9, 2018

9. Ghogawala Z, Resnick DK, Watters WC III, Mummaneni PV, Dailey AT, Choudhri TF, et al: Guideline update for the performance of fusion procedures for degenerative disease of the lumbar spine. Part 2: Assessment of functional outcome following lumbar fusion. J Neurosurg Spine 21:7-13, 2014

10. Hassard J, Teoh KRH, Visockaite G, Dewe P, Cox T: The cost of work-related stress to society: a systematic review. J Occup Health Psychol 23:1-17, 2018

11. Horppu R, Martimo K-P, Viikari-Juntura E, Lallukka T, MacEachen E: Occupational physicians' reasoning about recommending early return to work with work modifications. PLoS One 11:e0158588, 2016

12. Kaiser Family Foundation: State Health Facts. Data Source: Kaiser Family Foundation estimates based on the Census Bureau's American Community Survey, 2008-2018. KFF. org (https://www.kff.org/other/state-indicator/total-population/) [Accessed March 11, 2020]

13. Kim EJ, Chotai S, Wick JB, Khan I, Sivaganesan A, Bydon $\mathrm{M}$, et al: Factors associated with return-to-work following cervical spine surgery in non-Worker's compensation setting. Spine (Phila Pa 1976) 44:903-907, 2019

14. Liow MHL, Goh GS, Yeo W, Ling ZM, Yue WM, Guo CM, et al: Time taken to return to work does not influence outcomes of minimally invasive transforaminal lumbar interbody fusion: a 5-year follow-up study. Spine (Phila Pa 1976) 44:503-509, 2019

15. MacEachen E, Ferrier S, Kosny A, Chambers L: A deliberation on 'hurt versus harm' logic in early-return-to-work policy. Policy Pract Health Safety 5:41-62, 2007

16. McGirt MJ, Sivaganesan A, Asher AL, Devin CJ: Prediction model for outcome after low-back surgery: individualized likelihood of complication, hospital readmission, return to work, and 12-month improvement in functional disability. Neurosurg Focus 39(6):E13, 2015

17. Mummaneni PV, Bisson EF, Kerezoudis P, Glassman S, Foley K, Slotkin JR, et al: Minimally invasive versus open fusion for grade I degenerative lumbar spondylolisthesis: analysis of the Quality Outcomes Database. Neurosurg Focus 43(2):E11, 2017

18. Mummaneni PV, Bydon M, Alvi MA, Chan AK, Glassman $\mathrm{SD}$, Foley KT, et al: Predictive model for long-term patient satisfaction after surgery for grade I degenerative lumbar spondylolisthesis: insights from the Quality Outcomes Database. Neurosurg Focus 46(5):E12, 2019

19. Padua R, Padua L, Ceccarelli E, Romanini E, Bondì R, Zanoli $\mathrm{G}$, et al: Cross-cultural adaptation of the lumbar North American Spine Society questionnaire for Italian-speaking patients with lumbar spinal disease. Spine (Phila Pa 1976) 26:E344-E347, 2001

20. Parker SL, Godil SS, Zuckerman SL, Mendenhall SK, Devin $\mathrm{CJ}$, McGirt MJ: Extent of preoperative depression is associated with return to work after lumbar fusion for spondylolisthesis. World Neurosurg 83:608-613, 2015

21. Sarasqueta C, Gabaldon O, Iza I, Béland F, Paz PM: Crosscultural adaptation and validation of the NASS outcomes in- 
strument in Spanish patients with low back pain. Eur Spine J 14:586-594, 2005

22. Slotkin JR, Ross OA, Coleman MR, Ryu J: Why GE, Boeing, Lowe's, and Walmart are directly buying health care for employees. Harvard Business Review (https://hbr.org/2017/06/ why-ge-boeing-lowes-and-walmart-are-directly-buyinghealth-care-for-employees) [Accessed March 11, 2020]

23. Slotkin JR, Ross OA, Newman ED, Comrey JL, Watson V, Lee RV, et al: Episode-based payment and direct employer purchasing of healthcare services: recent bundled payment innovations and the Geisinger Health System experience. Neurosurgery 80 (4S):S50-S58, 2017

24. Steenstra IA, Munhall C, Irvin E, Oranye N, Passmore S, Van Eerd D, et al: Systematic review of prognostic factors for return to work in workers with sub acute and chronic low back pain. J Occup Rehabil 27:369-381, 2017

25. Tanenbaum SJ: What is the value of value-based purchasing? J Health Polit Policy Law 41:1033-1045, 2016

26. Than KD, Curran JN, Resnick DK, Shaffrey CI, Ghogawala Z, Mummaneni PV: How to predict RTW after lumbar discectomy: answers from the NeuroPoint-SD registry. J Neurosurg Spine 25:181-186, 2016

27. Woods L, Slotkin JR, Coleman MR: How employers are fixing healthcare. Harvard Business Review (https://hbr.org/ cover-story/2019/03/how-employers-are-fixing-health-care) [Accessed March 11, 2020]

28. Zakaria HM, Mansour TR, Telemi E, Asmaro K, Macki M, Bazydlo M, et al: Use of Patient Health Questionnaire-2 scoring to predict patient satisfaction and RTW up to 1 year after lumbar fusion: a 2-year analysis from the Michigan Spine Surgery Improvement Collaborative. J Neurosurg Spine 30:794-801, 2019

\section{Disclosures}

The study as a whole was supported by the Neurosurgery Research \& Education Foundation (NREF). Dr. Chan has received research support for a nonrelated study from Orthofix Inc. Dr. Bisson has received consultation fees from nView. Dr. $\mathrm{Fu}$ has received consultation fees from SI-BONE. Dr. Park has received consultation fees from Globus, NuVasive, Allosource, and Medtronic; he has also received royalties from Globus. Dr. Glassman is an employee of Norton Healthcare and is a patent holder with and has received consultation fees and royalties from Medtronic and NuVasive (provides funds directly to the database company; no funds are paid directly to individual or institution); he is also the past president of the Scoliosis Research Society. Dr. Foley has received consultation fees from, has direct stock ownership in, and is patent holder with Medtronic; he also has direct stock ownership in NuVasive and Spine Wave. Dr. Slotkin has received consultation fees from Stryker Spine. Dr. C. I. Shaffrey has direct stock ownership in, has received consultation fees from, and is a patent holder with NuVasive; he has received consultation fees from Zimmer Biomet; and he is a patent holder with Medtronic and Zimmer Biomet. Dr. Coric has received consultation fees from and has direct stock ownership in Spine Wave and Premia Spine; he has received consultation fees from Stryker and Medtronic; and he has direct stock ownership in Spinal Kinetics. Dr. Knightly is on the NPA board of directors. Dr. Wang is patent holder for and has received royalties from DePuy Synthes Spine; he has received consultation fees from DePuy Synthes Spine, JoiMax, K2M, and Aesculap Spine; he is on the medical advisory board of Vallum; he has direct stock ownership in Spinicity; and he has received grants from the Department of Defense. Dr. Haid has received consultation fees and royalties from NuVasive; he has ownership interest in Spine Universe; and he has received royalties from Medtronic Sofamor Danek. Dr. Mummaneni has received consultation fees from DePuy Spine, Globus, and Stryker; he has direct stock ownership in Spinicity/ISD; he has received clinical/research support for this study from NREF; he has received royalties from DePuy Spine, Thieme Publishers, and Springer Publishers; he has received a grant from AOSpine; and he has received honoraria from Spineart.

\section{Author Contributions}

Conception and design: DiGiorgio, Mummaneni, Park, Chan, Slotkin. Acquisition of data: Mummaneni, Park, Chan, Bisson, Bydon, Foley, CI Shaffrey, Potts, ME Shaffrey, Coric, Knightly, Wang, Fu, Asher, Virk, Kerezoudis, Alvi, Guan, Haid. Analysis and interpretation of data: DiGiorgio, Mummaneni, Park, Chan, Alvi, Slotkin. Drafting the article: DiGiorgio. Critically revising the article: DiGiorgio, Mummaneni, Park, Chan, Alvi, Haid, Slotkin. Reviewed submitted version of manuscript: DiGiorgio, Mummaneni, Park, Chan, Bisson, Bydon, Foley, CI Shaffrey, Potts, ME Shaffrey, Coric, Wang, Fu, Glassman, Asher, Virk, Kerezoudis, Alvi, Guan, Haid, Slotkin. Approved the final version of the manuscript on behalf of all authors: DiGiorgio. Statistical analysis: DiGiorgio, Chan, Slotkin. Administrative/technical/ material support: Mummaneni, Park, Bisson, Bydon, Foley, CI Shaffrey, Potts, ME Shaffrey, Coric, Knightly, Wang, Fu, Glassman, Asher, Virk, Guan, Haid, Slotkin. Study supervision: Mummaneni, Park, Knightly, Slotkin.

\section{Correspondence}

Anthony M. DiGiorgio: San Francisco General Hospital, University of California, San Francisco, CA. anthony.digiorgio@ ucsf.edu. 